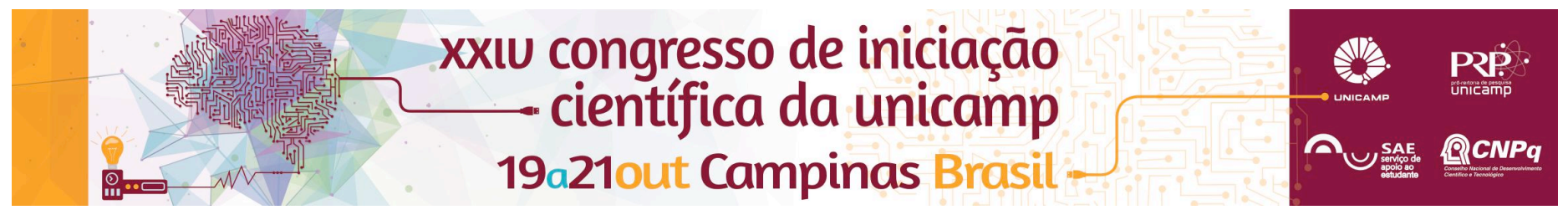

\title{
Caracterização do sistema de detecção de fótons do experimento DUNE
}

\author{
Thales Vanzo Vieira*, Ernesto Kemp
}

\section{Resumo}

A física de partículas passou por grandes avanços teóricos e experimentais desde a descoberta de partículas subatômicas. Um exemplo deste progresso foi a comprovação de que neutrinos existem e possuem massa não nula. Ainda hoje o estudo acerca de neutrinos é intenso e promissor. Grandes colaborações - como DUNE, ProtoDUNE, SBND e LArIAT - contribuem intensamente para o desenvolvimento da técnica inovadora de câmaras projeção temporal de argônio líquido (LArTPC). A UNICAMP é membro das colaborações citadas, portanto neste projeto foram estudadas a produção de fibras ópticas dopadas com deslocador de comprimento de onda em extrusora vertical afim de coletar fótons provenientes da cintilação do argônio líquido devido à interações de neutrinos em uma LArTPC.

\section{Palavras-chave:}

Neutrinos, Experimento DUNE, Detectores de argônio líquido.

\section{Introdução}

A tecnologia de câmaras de projeção temporal de argônio líquido (LArTPC) é a nova opção para detectores de partículas que estão em construção ou funcionamento nos laboratórios FERMILAB (USA) e CERN (UE). Estes detectores consistem em um conjunto de sensores e equipamentos de alta precisão que devem trabalhar de forma sincronizada para detectar interações de neutrinos com núcleos de argônio. Um dos principais sistemas que será responsável por esta sincronia é o de detecção de fótons, pois a partir de uma interação de neutrino com argônio líquido, espera-se que haja cintilação e/ou ionização do mesmo. Desta forma, como o deslocamento da luz é feito de forma mais ágil do que o arraste de elétrons dentro da câmara, os fótons provenientes da cintilição funcionarão como parâmetro inicial (trigger) de interações dentro da câmara.

Neste projeto buscamos construir e estudar fibras ópticas dopadas afim de serem os coletores de luz nas LArTPCs de colaborações internacionais nos laboratórios citados. A dopagem é essencial para as fibras dado que o comprimento de fótons emitidos pelo argônio não são visíveis às fotomultiplicadoras de silício, as quais serão implementadas nos detectores.

\section{Resultados e Discussão}

Foram produzidas diversas fibras ópticas não dopadas através de uma extrusora vertical. Testes de transmitância de luz e polimento de suas faces foram realizados e analisados. Será realizado teste de resistência mecânica à baixa temperatura.

A produção de fibras ópticas dopadas se dá através de um processo intermediário em que são feitos filmes finos com PMMA, material base das fibras, acetona e deslocador de comprimento de onda. Porém diversos testes indicaram a presença de acetona nos filmes após tratamento térmico, que faz a transmitância de luz na fibra cair a poucos centímetros. Até o momento não foi encontrada a solução para este problema, mas estou em contato com professores da Faculdade de Engenharia Química (FEQ - Unicamp) para solucionar este problema.

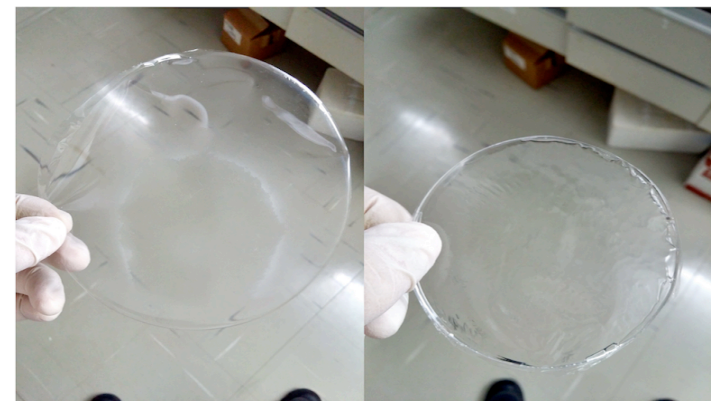

Figura 1. Filmes finos de PMMA que apresentam acetona em sua composição.

Tabela 1: Dados sobre polimento e transmitância óptica em uma fibra cilíndrica sem deslocador.

\begin{tabular}{cccc}
\hline Polimento & Perda $(\mathrm{dB} / \mathrm{m})$ & Comprimento $(\mathrm{cm})$ & Diâmetro (m \\
\hline Pol. + kaol & 2.779 & 107.8 & 4.4 \\
Pol. + kaol + A.T. & 2.576 & 107.8 & 4.4 \\
Pol. + água + lixa 4000 & 2.499 & 107.8 & 4.4 \\
\hline Pol. = Politris & A.T. $=$ assoprador térmico &
\end{tabular}

\section{Conclusões}

É necessário mais tempo para que o projeto tenha sua concretização. Um novo método de produção de fibras será testado. Contudo, o método atual será necessário como passo intermediário para o novo processo. Apesar de não produzir fibras dopadas, as fibras feitas apresentam resultado comparável com os métodos de coleção de luz utilizados em experimentos solidificados [1].

\section{Agradecimentos}

Agradeço ao meu orientador Erneto Kemp pela responsabilidade a mim confiada, assim como aos colegas de trabalho. Ao SAE que me privilegiou com uma bolsa de IC e à todos os meu amigos que me ajudaram a ser quem sou.

\footnotetext{
${ }^{1}$ Ettore Segretto - comunicação pessoal
} 